Article

\title{
Multidrug-Resistant and Genetic Characterization of Extended-Spectrum Beta-Lactamase-Producing $E$. coli Recovered from Chickens and Humans in Egypt
}

\author{
Heba Badr ${ }^{1}$, Reem M. Reda ${ }^{1}$, Naglaa M. Hagag ${ }^{1}$, Essam Kamel ${ }^{2}$ D, Sara M. Elnomrosy ${ }^{3}$, Amal I. Mansour ${ }^{4}$ (D), \\ Momtaz A. Shahein ${ }^{5}$, Samah F. Ali ${ }^{6}$ (D) and Hala R. Ali ${ }^{6, *(D)}$
}

check for updates

Citation: Badr, H.; Reda, R.M.; Hagag, N.M.; Kamel, E.; Elnomrosy, S.M.; Mansour, A.I.; Shahein, M.A.;

Ali, S.F.; Ali, H.R. Multidrug-Resistant and Genetic Characterization of Extended-Spectrum Beta-Lactamase-Producing E. coli Recovered from Chickens and Humans in Egypt. Animals 2022, 12, 346. https://doi.org/10.3390/ ani12030346

Academic Editor: Alessandra Piccirillo

Received: 18 December 2021

Accepted: 25 January 2022

Published: 31 January 2022

Publisher's Note: MDPI stays neutral with regard to jurisdictional claims in published maps and institutional affiliations.

Copyright: (c) 2022 by the authors. Licensee MDPI, Basel, Switzerland. This article is an open access article distributed under the terms and conditions of the Creative Commons Attribution (CC BY) license (https:// creativecommons.org/licenses/by/ $4.0 /)$.
1 Reference Laboratory for Veterinary Quality Control on Poultry Production, Animal Health Research Institute, Agriculture Research Center (ARC), Giza 12618, Egypt; drheba_badr@yahoo.com (H.B.); reda_reem@yahoo.com (R.M.R.); naglaahagagahri@gmail.com (N.M.H.)

2 Department of chemistry, Animal Health Research Institute, Agriculture Research Center (ARC), Giza 12618, Egypt; essamkamel1@yahoo.com

3 Genome Research Unit, Animal Health Research Institute, Agriculture Research Center (ARC), Giza 12618, Egypt; dr_sara_vet_2007@yahoo.com

4 Bacteriology, Food and Agriculture Organization of the United Nations, Giza 2223, Egypt; Amal.Mansour@fao.org

5 Department of Virology Research, Animal Health Research Institute, Agriculture Research Center (ARC), Giza 12618, Egypt; momtaz.shahein@yahoo.com

6 Bacteriology Department, Animal Health Research Institute (AHRI), Agriculture Research Center (ARC), Giza 12618, Egypt; samah_hefny2004@yahoo.com

* Correspondence: alihala312@gmail.com

Simple Summary: Feeding food chain animals with sub-therapeutic doses for prophylaxis or for growth-promoting purposes has led to the emergence of resistant bugs such as ESBL-E. coli. Infections caused by these superbugs are tremendously associated with treatment failures and high morbidity/mortality rates. Scarce information is currently available on the relation between the incidence of ESBL-E. coli in human and food chain animals in Egypt. The current study analyzed chicken and human fecal samples for isolation and characterization of ESBL-producing E. coli followed by sequencing the isolates. Significant similarities were detected between human and chicken isolates, indicating the possibility of zoonotic transmission. In conclusion, the study encouraged managing the use of antibiotics in veterinary field, to reduce the selection and spread of life-threating bugs to humans.

Abstract: Colonization of food chain animals such as chickens with extended-spectrum $\beta$-lactamases (ESBL) poses a major health threat to human. The current study aimed to determine the phenotypic and genotypic relationship between ESBL-producing E. coli from diseased human and chickens in Egypt. A total of 56 out of 120 chicken farms (46.7\%) and 9 human samples (100\%) were phenotypically and genotypically identified with at least one ESBL-phenotype/gene. Chicken isolates showed a high proportion of beta lactamase from CTX-M group $9>$ TEM $>$ PER families, followed by CTXM group $1>$ SHV > GES > OXA group10 > VEB > OXA group2 families, while human isolates only contained the CTX-M family. A high incidence of ESBL genes from the CTX-M family was recognized in both human and chicken isolates. Furthermore, nucleotide identity showed high similarity between chicken and human isolates. In conclusion, the current study traced phenotypes and genotypes of ESBL-producing E. coli from chickens and human samples in Egypt, reporting degrees of similarity that suggest potential zoonotic transmission. Our data highlighted the significant importance of chicken as a major food source not only in Egypt but all over the world in the spreading of ESBL-producing E. coli to human.

Keywords: antibiotic resistance; E. coli; ESBL; poultry; human 


\section{Introduction}

Escherichia coli is a member of the family Enterobacteriaceae which causes enteric and extraintestinal infections in both animals and humans [1]. The resistance of Enterobacteriacea to third- and fourth-generation cephalosporins via the production of extended-spectrum $\beta$-lactamases (ESBLs) has raised since the 2000s, limiting therapeutic options against these infections [2]. The potential zoonotic importance of E. coli either from animals or food derived from animals has been previously documented. In the last two decades, E. coliproducing ESBLs have been reported widely in animals as well as humans possessing a serious public-health threat $[3,4]$.

Due to the global spread of antibiotic-resistance bacteria, the World Health Organization (WHO), Food and Agriculture Organization of the United Nation (FAO), and World Organization for Animal Health (OIE) have coined the "One Health" approach, which includes collaborative efforts from the environment, animal, and human health authorities to limit the spread of this phenomenon [5,6]. Various scenarios have shown that close contact between humans and infected livestock contributes to spreading of resistant bacteria including ESBL-producing E. coli. Since human and animals share the same environment, they potentially share resistant bacteria and resistant genes [7]. It has been shown that poultry and poultry by-products act as a potential source of antibiotic-resistant bacteria, including ESBL-producing E. coli, to humans [8].

Nine distinct structural and evolutionary families of ESBL variants were reported based on amino acid sequence comparisons, such as TEM, SHV, CTX-M, PER, VEB, GES, BES, TLA, and OXA. The major ESBL variants are TEM, SHV, CTX-M, and OXA. The $b l a_{C T X-M}$ variant is rapidly spreading and widely reported in E. coli around the globe [9]. African countries have reported a significant incidence of ESBL-producing E. coli among humans and animals. ESBL-E. coli with bla $a_{C T X-M}, b l a_{S H V}$, and bla $a_{T E M}$ genes were previously detected in 20.1\% chicken markets in Zambia [10]. In Ghana, ESBL-producing E. coli were found in humans and broilers chickens harboring bla of studies suggested that chicken meat and meat products might be a potential source of ESBL-bacteria transmission to humans in Africa [11,12]. Comparable analysis conducted in central Europe demonstrated genetic similarity in ESBL-producing E. coli from Mongolian migratory birds and clinical isolate from hospitalized human in Europe [13]. Additionally, number of studies have shown frequent colonization of poultry with ESBL-producing E. coli $[14,15]$, which puts humans in contact with and consumers at risk of acquiring ESBL infections. In support, an association has been noticed between the colonization of chicken retail meat with ESBL-producing E. coli and a high incidence of ESBL infections in hospitalized patients in the Netherlands [16].

In Egypt, ESBL-producing E. coli was previously reported in chickens, chicken meat [17,18], and humans [3], which highlights the importance of continuous monitoring ESBL-producing E. coli in both animals and humans. Hence, this study was aimed to investigate the phenotypic and genotypic characteristics of ESBL-producing E. coli samples obtained from diseased chickens and compared with samples retrieved from human cases in Egypt in the period between 2019 and 2020.

\section{Materials and Methods}

\subsection{Sample Collection}

A total of 120 diseased broiler chicken farms (five chickens from each farm and the age of birds varied from 7 to 35 days) suffered from ruffled feathers, depression, and loss of appetite. Samples were collected from different geographical locations in the northern part of Egypt (Dakahlia, Giza, and Sharqia Governorates) between September 2019 to December 2020. Birds were transported to the Reference Laboratory for Veterinary Quality Control on poultry production and further subjected to post mortem examination under septic conditions. Samples were obtained from internal organs (liver, lung, spleen, and heart) from birds showing colisepticemia, air sacculitis, perihepatitis, and pericarditis and pooled together for bacterial screening and isolation. In parallel, nine stool samples were 
collected from diseased humans from Qena. All samples collection procedures were legally approved by the Committee of Ethics at the Animal Health Research Institute, Egypt, under protocol number (AHRI-42429).

\subsection{Isolation and Identification}

E. coli was isolated and identified as described elsewhere [19]. Briefly, samples were incubated aerobically into buffer peptone water at $37^{\circ} \mathrm{C}$ for $24 \mathrm{~h}$. A loopful from each incubated sample was streaked onto MacConkey's agar (Oxoid, Manchester, UK) and Eosin Methylene Blue agar (Lioflichem, Roseto degli Abruzzi, Italy) plates were then incubated at $37^{\circ} \mathrm{C}$ for $24 \mathrm{~h}$. The suspected colonies were 1-2 mm diameter, and appeared as a hot-pink color colony on MacConkey and metallic sheen colonies on Eosin Methylene Blue agar. Suspected E. coli colonies were subjected for further biochemical examination (indole test, methyl red, voges Proskauer "VP", citrate utilization, oxidase test, and Triple Sugar Iron "TSI"). Furthermore, serotyping of isolated E. coli was performed using Somatic (O) antigens and antiserum according to the kit instruction of (DENKA SEIKEN Co., Tokyo, Japan).

\subsection{Antimicrobial Susceptibility Pattern and ESBL Screening of the Isolated E. coli}

\subsubsection{Antimicrobial Sensitivity Test (AST)}

AST was performed for all isolates by the disc diffusion test as previously described [20] against 14 antibiotics (Oxoid, Basingstoke, UK). Furthermore, initial ESBL screening was carried out for all isolates by disc diffusion method based on various cephalosporins according to the Clinical and Laboratory Standards Institute (CLSI) standard [21]. Isolates with an inhibition zone size of $\leq 22 \mathrm{~mm}$ with ceftazidime (30 $\mu \mathrm{g}), \leq 25 \mathrm{~mm}$ with ceftriaxone $(30 \mu \mathrm{g}), \leq 27 \mathrm{~mm}$ with cefotaxime $(30 \mu \mathrm{g})$, and $\leq 27 \mathrm{~mm}$ with Aztreonam $(30 \mu \mathrm{g})$ were identified as potential ESBL producers.

\subsubsection{Double Disc Synergy Test (DDST)}

To confirm ESBL production, DDST was performed as described elsewhere [22]. Briefly, Amoxicillin-clavulanic acid (AMC, $30 \mu \mathrm{g}$ ) applied with a distance $20 \mathrm{~mm}$ center-tocenter to that of each antibiotic disc $(30-\mu \mathrm{g})$ of third-generation cephalosporin (Cefotaxime and Ceftriaxone) and fourth-generation cephalosporins (Ceftazidime and Cefepime) on Mueller-Hinton Agar (MHA) plates. Clear extension of the edge of the inhibition zone of cephalosporin toward the AMC disc was interpreted as positive for ESBL production.

HiCrome ESBL agar (Himedia ${ }^{\circledR}$, Mumbai, India). This test was also used for identification of ESBL E. coli. It is a rapid test, as it gives a result in approximately $24 \mathrm{~h}$. ESBL E. coli producers show pink or purple colonies.

\subsection{Genotypic Characterizations of ESBL}

All isolates were initially tested using polymerase chain reaction (PCR) specific for the presence of ESBL genes: bla $a_{T E M}, b l a_{S H V}, b l a_{C T X-M}, b l a_{O X A}, b l a_{G E S}, b l a_{V E B}$, and $b l a_{P E R}$, as described previously $[9,23]$. Briefly, DNA extraction was performed using QIAamp DNA extraction Kit (Qiagen, Hilden, Germany) according to the manufacturer's instructions. The extracted DNA was further tested using gene-specific PCR assays using COSMO PCR RED Master Mix (Willowfort, Birmingham, UK). Amplification was performed using Bio-Rad thermal cycler and consisted of an initial denaturation ( 1 cycle) for $10 \mathrm{~min}$ at $95^{\circ} \mathrm{C}$ followed by 35 cycles of denaturation: $96^{\circ} \mathrm{C} / 3 \mathrm{~s}$, annealing: $58-67^{\circ} \mathrm{C} / 10 \mathrm{~s}$, extension: $68^{\circ} \mathrm{C} / 15 \mathrm{~s}$; and a final extension cycle for $15 \mathrm{~s}$ at $72{ }^{\circ} \mathrm{C}$. Primers used with different annealing temperature are detailed in Table 1.

Six housekeeping genes $a d k, f u m C, g y r B, i c d, m d h$, and $p u r A$ were amplified for three chicken and two human isolates using primers previously described by [24]. Amplification was carried out in a $50 \mu \mathrm{L}$ reaction containing $25 \mu \mathrm{L}$ of COSMO PCR RED Master Mix (Cat. No. 1020300X), $2.5 \mu \mathrm{L}$ of each primer set, $5 \mu \mathrm{L}$ of the DNA sample, and nuclease-free water, with the thermal protocol: $95^{\circ} \mathrm{C}$ for $2 \mathrm{~min}, 35$ cycles of $95^{\circ} \mathrm{C}$ for $15 \mathrm{~s}$, annealing temperature depended upon the specific primers $\left(58-60{ }^{\circ} \mathrm{C}\right), 72{ }^{\circ} \mathrm{C}$ for $1 \mathrm{~min}$, and $72{ }^{\circ} \mathrm{C}$ for 
10 min. The PCR products were separated by 1.5\% agarose gel electrophoresis (AppliChem, Darmstadt, Germany). A gene ruler 100 bp DNA ladder (Fermentas, Thermo, Offenbach, Germany) was used to determine the fragment size. The gel was photographed using a gel documentation system (Alpha Innotech, Biometra, South San Francisco, CA, USA) ${ }^{\mathrm{TM}}$, and size-specific DNA bands were excised and purified from gels using the QIAquick Gel Extraction Kit (Qiagen, Hilden, Germany). The purified products were used directly for cycle sequencing reactions using BigDye Terminator v3.1 Cycle Sequencing Kit (Applied Biosystems, Waltham, MA, USA). This was done by adding 2 BigDye 3.1 Sequencing Buffer, $1 \mu \mathrm{L}$ BigDye Terminator, $3.2 \mathrm{pmol}$ of the forward primer, and $3 \mu \mathrm{L}$ of purified PCR product in a $10-\mu \mathrm{L}$ reaction. The sequencing reaction was performed in 25 cycles of $96{ }^{\circ} \mathrm{C}$ for $15 \mathrm{~s}, 50{ }^{\circ} \mathrm{C}$ for $10 \mathrm{~s}$, and $60{ }^{\circ} \mathrm{C}$ for $4 \mathrm{~min}$. Reaction products were then purified using a Centrisep spin column (Applied Biosystems, Waltham, MA, USA) and sequenced on an ABI PRISM 3500 Genetic Analyzer (Life Technologies, Carlsbad, CA, USA). Thereafter, the obtained sequences were assembled and aligned using the Geneious Prime software, version 2021.1.1. https: / / www.geneious.com (accessed on 14 November 2021). BLAST®https: / / blast.ncbi.nlm.nih.gov / (accessed on 14 November 2021) analysis of the obtained nucleotide sequences was performed to check sequence identities. In addition, identity matrices between chicken and human isolates were calculated and visualized with Geneious Prime software.

Table 1. Specific primers for ESBL genes detection.

\begin{tabular}{|c|c|c|c|c|}
\hline Gene & Sequence $\left(5^{\prime}-3^{\prime}\right)$ & $\begin{array}{c}\text { Temperatures of } \\
\text { Annealing Step }\left({ }^{\circ} \mathrm{C}\right)\end{array}$ & $\begin{array}{l}\text { Product } \\
\text { Size }\end{array}$ & References \\
\hline $\begin{array}{l}b l a_{T e M-\mathrm{F}} \\
b l a_{T e M-\mathrm{R}}\end{array}$ & $\begin{array}{l}\text { ATG AGT ATT CAA CAT TTC CGT } \\
\text { TTA CCA ATG CTT AAT CAG TGA }\end{array}$ & 58 & $861 \mathrm{bp}$ & [23] \\
\hline bla & $\begin{array}{l}\text { GCC AGA ATA GGA GTA GCA AT } \\
\text { TGG ACT CTG CAA CAA ATA CG }\end{array}$ & 58 & $703 \mathrm{bp}$ & [9] \\
\hline $\begin{array}{l}\text { bla }_{\text {OXa2-F }} \\
\text { bla }_{\text {OXa2-R }}\end{array}$ & $\begin{array}{l}\text { ATG GCA ATC CGA ATC TTC GC } \\
\text { GCA CGA TTG CCT CCC TCT T }\end{array}$ & 60 & $670 \mathrm{bp}$ & [9] \\
\hline $\begin{array}{l}b l a_{O X a 10-\mathrm{F}} \\
b l a_{O X a 10-\mathrm{R}}\end{array}$ & $\begin{array}{l}\text { ATG AAA ACA TTT GCC GCA TAT G } \\
\text { TTA GCC ACC AAT GAT GCC CT }\end{array}$ & 60 & $801 \mathrm{bp}$ & [9] \\
\hline $\begin{array}{l}\text { bla ges-F } \\
\text { blages-R }\end{array}$ & $\begin{array}{l}\text { TAC TGG CAG SGA TCG CTC AC } \\
\text { TTG TCC GTG CTC AGG ATG AG }\end{array}$ & 62 & $838 \mathrm{bp}$ & [9] \\
\hline $\begin{array}{l}\text { bla } \\
\text { bla } a_{P e R-\mathrm{F}}\end{array}$ & $\begin{array}{l}\text { CTC AGC GCA ATC CCC ACT GT } \\
\text { TTG GGC TTA GGG CAG AAA GCT }\end{array}$ & 62 & $851 \mathrm{bp}$ & [9] \\
\hline $\begin{array}{l}b l a_{\operatorname{sh} V-\mathrm{F}} \\
b l a_{s h V-\mathrm{R}}\end{array}$ & $\begin{array}{l}\text { CGC CTG TGT ATT ATC TCC CTG } \\
\text { TTA GCG TTG CCA GTG CTC GAT }\end{array}$ & 64 & $849 \mathrm{bp}$ & [9] \\
\hline $\begin{array}{l}\text { bla } \\
\text { bla CTX-M 1-F } \\
\text { CTX-M 1-R }\end{array}$ & $\begin{array}{l}\text { AGT TCA CGC TGA TGG CGA CG } \\
\text { GAC GAT TTT AGC CGC CGA CG }\end{array}$ & 67 & $839 \mathrm{bp}$ & [9] \\
\hline $\begin{array}{l}\text { bla } \\
\text { blaCTX-M 9-F } \\
\text { ClX-M 9-R }\end{array}$ & $\begin{array}{l}\text { GCG TGC ATT CCG CTG CTG C } \\
\text { ACA GCC CTT CGG CGA TGA TTC }\end{array}$ & 67 & $832 \mathrm{bp}$ & [9] \\
\hline
\end{tabular}

\section{Results}

\subsection{E. coli Isolation, Identification, and Serotyping}

Fifty-six farms were positive for E. coli isolation with a percentage of $46.7 \%$. E. coli isolates were reported from internal organs (liver, lung, spleen, and heart) of 120 diseased broiler chickens that collected from farms located in Dakahlia, Giza, and Sharqia governorates; E. coli isolates were identified TSI acidic at slant and bottom with gas production, positive for catalase, methyl red, and indole, while negative for VP, oxidase, and citrate.

The chicken isolates were differentiated serologically and revealed different serotypes: O18 $(n=4)$, O55 $(n=8)$, O86a $(n=7)$, O111 $(n=6)$, O125 $(n=18)$, O127 $(n=5)$, O157 $(n=2), \mathrm{O} 159(n=4)$, and $\mathrm{O} 166(n=2)$. On the other hand, all the nine human samples were positive for E. coli with the following different serotypes: O44 $(n=1), \mathrm{O} 55(n=3), \mathrm{O} 86 \mathrm{a}$ $(n=2), \mathrm{O} 164(n=2)$, and O119 $(n=1)$. 


\subsection{Antimicrobial Susceptibility Pattern of the Isolated E. coli}

\subsubsection{Antimicrobial Sensitivity Test (AST)}

A total of 56 chicken and 9 human E. coli isolates were analyzed. A similar trend was observed among the chicken and human isolates where the majority of the isolates were resistant to cephalexin, cephalothin, ampicillin, amoxicillin-clavulanic acid, sulfamethoxazoletrimethoprim, and cefotaxime, as shown in Table 2, with percentages of 100, 100, 92.9, 96.4, 82.1 , and $76.8 \%$, respectively, in chicken isolates and $100,100,100,33.3,55.6$, and $55.6 \%$, respectively, in human isolates. Detailed percentage of resistant, intermediate, and sensitive isolates to each antibiotic is outlined in Table 2 according to the CLSI standard.

Table 2. Antimicrobial susceptibility pattern of the isolated E. coli from poultry and human.

\begin{tabular}{|c|c|c|c|c|c|c|}
\hline \multirow[t]{2}{*}{ Antimicrobial Agent } & \multicolumn{2}{|c|}{$\begin{array}{l}\text { Resistant } \\
\text { No. }(\%)^{1}\end{array}$} & \multicolumn{2}{|c|}{$\begin{array}{l}\text { Intermediate } \\
\text { No. }(\%)^{1}\end{array}$} & \multicolumn{2}{|c|}{$\begin{array}{l}\text { Sensitive } \\
\text { No. }(\%)^{1}\end{array}$} \\
\hline & Poultry $(n=56)$ & Human $(n=9)$ & Poultry $(n=56)$ & Human $(n=9)$ & Poultry $(n=56)$ & Human $(n=9)$ \\
\hline $\begin{array}{l}\text { Amoxicillin-clavulanic acid } \\
\qquad\left(\mathrm{AMC}^{30}\right)\end{array}$ & $54(96.4 \%)$ & $3(33.3 \%)$ & $2(3.6 \%)$ & $1(11.1 \%)$ & 0 & $5(55.6 \%)$ \\
\hline Ampicillin $\left(\mathrm{AMP}^{10}\right)$ & $52(92.9 \%)$ & $9(100 \%)$ & $4(7.1 \%)$ & $0(0 \%)$ & 0 & $0(0 \%)$ \\
\hline Aztreonam $\left(\mathrm{ATM}^{30}\right)$ & $18(32.1 \%)$ & $2(22.2 \%)$ & $6(10.7 \%)$ & $2(22.2 \%)$ & $32(57.2 \%)$ & $5(55.6 \%)$ \\
\hline Cefepime $\left(\mathrm{FEP}^{30}\right)$ & $20(35.7 \%)$ & $3(33.3 \%)$ & $24(42.9 \%)$ & $3(33.3 \%)$ & $12(21.4 \%)$ & $3(33.3 \%)$ \\
\hline Cefotaxime $\left(\mathrm{CTX}^{30}\right)$ & $43(76.8 \%)$ & $5(55.6 \%)$ & $9(16.1 \%)$ & $2(22.2 \%)$ & $4(7.1 \%)$ & $2(22.2 \%)$ \\
\hline Ceftazidime $\left(\mathrm{CAZ}^{30}\right)$ & $30(53.6 \%)$ & $4(44.4 \%)$ & $16(28.6 \%)$ & $4(44.4 \%)$ & $10(17.8 \%)$ & $1(11.1 \%)$ \\
\hline Ceftriaxone $\left(\mathrm{CRO}^{30}\right)$ & $25(44.7 \%)$ & $3(33.3 \%)$ & $11(19.6 \%)$ & $0(0 \%)$ & $20(35.7 \%)$ & $6(66.7 \%)$ \\
\hline Cephalexin $\left(\mathrm{CL}^{30}\right)$ & $56(100 \%)$ & $9(100 \%)$ & $0(0 \%)$ & $0(0 \%)$ & $0(0 \%)$ & $0(0 \%)$ \\
\hline Cephalothin $\left(\mathrm{KF}^{30}\right)$ & $56(100 \%)$ & $9(100 \%)$ & $0(0 \%)$ & $0(0 \%)$ & $0(0 \%)$ & $0(0 \%)$ \\
\hline Ciprofloxacin $\left(\mathrm{CIP}^{5}\right)$ & $37(66.1 \%)$ & $1(11.1 \%)$ & $7(12.5 \%)$ & $0(0 \%)$ & $12(21.4 \%)$ & $8(88.9 \%)$ \\
\hline Colistin sulphate $\left(\mathrm{CT}^{10}\right)$ & $23(41.1 \%)$ & $0(0 \%)$ & $0(0 \%)$ & $0(0 \%)$ & $33(58.9 \%)$ & $9(100 \%)$ \\
\hline Imipenem $\left(\mathrm{IPM}^{10}\right)$ & $0(0 \%)$ & $0(0 \%)$ & $0(0 \%)$ & $0(0 \%)$ & $56(100 \%)$ & $9(100 \%)$ \\
\hline Norfloxacin $\left(\mathrm{NOR}^{10}\right)$ & $37(66.1 \%)$ & $1(11.1 \%)$ & $4(7.1 \%)$ & $0(0 \%)$ & $15(26.8 \%)$ & $8(88.9 \%)$ \\
\hline $\begin{array}{l}\text { Sulfamethoxazole- } \\
\text { trimethoprim (SXT }{ }^{25} \text { ) }\end{array}$ & $46(82.1 \%)$ & $5(55.6 \%)$ & $1(1.8 \%)$ & $0(0 \%)$ & $9(16.1 \%)$ & $4(44.4 \%)$ \\
\hline
\end{tabular}

${ }^{1}$ Percentage of positive samples.

\subsubsection{ESBL Screening Test}

The disc diffusion method with four cephalosporins, to detect ESBL, showed that the highest rate of resistance was against cefotaxime (94.6\%), followed by Aztreonam and ceftazidime $(85.7 \%)$ and then Ceftriaxone $(78.6 \%)$ for isolates obtained from chickens. Furthermore, E. coli isolated from the human samples showed resistance of Aztreonam and Cefotaxime (100\%), Ceftazidime (88.9\%), and Ceftriaxone (55.6\%) (Table 3).

Table 3. ESBL screening test using the disc diffusion method for isolates obtained from poultry and humans.

\begin{tabular}{|c|c|c|c|}
\hline \multirow{2}{*}{$\begin{array}{l}\text { Antibiotic Disc for } \\
\text { ESBL Screening Test }\end{array}$} & \multirow{2}{*}{$\begin{array}{c}\text { Interpretation of } \\
\text { Conduct ESBL-Testing }\end{array}$} & \multicolumn{2}{|c|}{ ESBL Production Screening } \\
\hline & & Poultry (\%) ${ }^{1}$ & Human (\%) ${ }^{1}$ \\
\hline Aztreonam $\left(\mathrm{ATM}^{30}\right)$ & $\leq 27 \mathrm{~mm}$ & $48(85.7 \%)$ & $9(100 \%)$ \\
\hline Cefotaxime $\left(\mathrm{CTX}^{30}\right)$ & $\leq 27 \mathrm{~mm}$ & $53(94.6 \%)$ & $9(100 \%)$ \\
\hline Ceftazidime $\left(\mathrm{CAZ}^{30}\right)$ & $\leq 22 \mathrm{~mm}$ & $48(85.7 \%)$ & $8(88.9 \%)$ \\
\hline Ceftriaxone $\left(\mathrm{CRO}^{30}\right)$ & $\leq 25 \mathrm{~mm}$ & $44(78.6 \%)$ & $5(55.6 \%)$ \\
\hline
\end{tabular}

${ }^{1}$ Percentage of positive samples from a total of 56 (chickens) and 9 (humans) tested samples.

\subsubsection{Double Disc Synergy Test (DDST)}

DDST was used for the confirmation of ESBL production. The sample is considered positive when the inhibition zones around any of the cephalosporin discs are augmented in the direction of the disc containing clavulanic acid, which detected a different percentage for each antibiotic disc, as shown in Table 4 and Figure 1. ESBL production, in at least one of the antibiotics, was found in $42 / 56(75 \%)$ of the chicken isolates and $8 / 9(88.9 \%)$ of the human isolates. 
Table 4. ESBL disc confirmation by the Double Disc SynergyTest (DDST). The confirmation was considered positive if the cephalosporin inhibition zone was extended toward the clavulanic acid antibiotic.

\begin{tabular}{|c|c|c|}
\hline \multirow{2}{*}{$\begin{array}{l}\text { Antibiotic Disc for ESBL } \\
\text { Screening Test }\end{array}$} & \multicolumn{2}{|c|}{ ESBL Production Confirmation } \\
\hline & Poultry $(\%)^{1}$ & Human $(\%)^{1}$ \\
\hline Cefepime $\left(\mathrm{CPM}^{30}\right)$ & $22(39.3 \%)$ & $8(88.9 \%)$ \\
\hline Cefotaxime $\left(\mathrm{CTX}^{30}\right)$ & $22(39.3 \%)$ & $7(77.8 \%)$ \\
\hline Ceftazidime $\left(\mathrm{CAZ}^{30}\right)$ & $20(35.7 \%)$ & $6(66.7 \%)$ \\
\hline Ceftriaxone $\left(\mathrm{CRO}^{30}\right)$ & $28(50 \%)$ & $8(88.9 \%)$ \\
\hline
\end{tabular}

$\overline{1}$ Percentage of positive samples from a total of 56 and 9 tested samples obtained from chickens and humans, respectively.
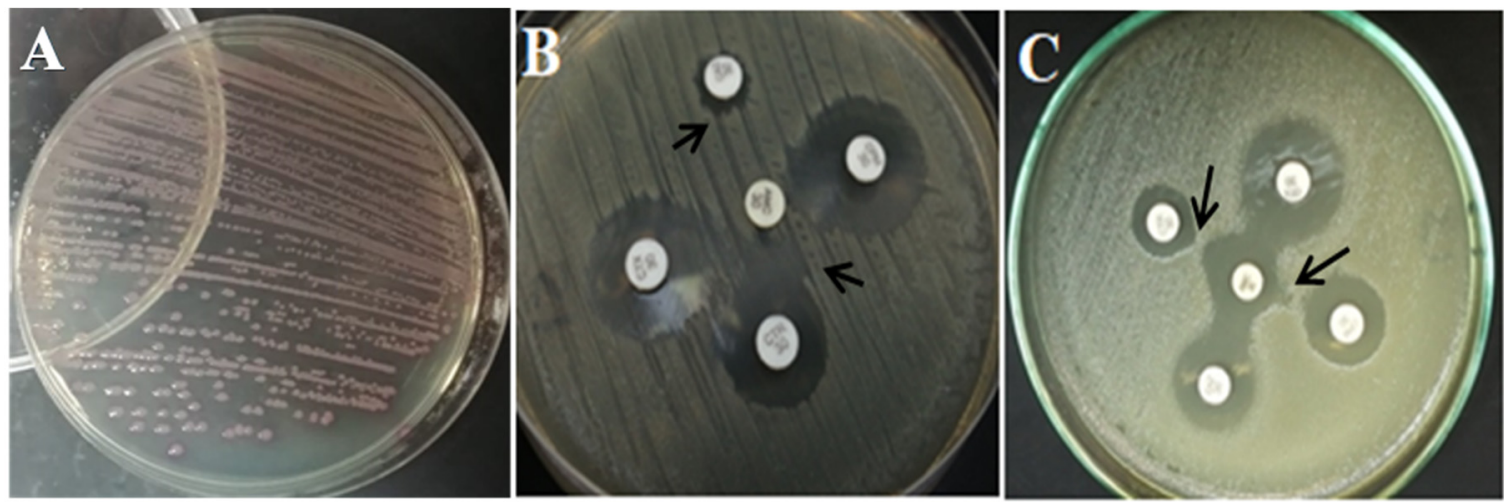

Figure 1. (A) E. coli on ESBL chromogenic agar. (B,C) Double Disc Synergy Test (DDST), which was done by using the DDST on four discs of cephalosporins antibiotic, i.e., cefotaxime, ceftriaxone, ceftazidime, and cefepime, against the amoxicillin-clavulanic acid. Black arrows show some synergistic pattern in the DDST.

Furthermore, all E. coli isolates from poultry and human were grown on the chromogenic agar, producing pink or purple colonies, indicating that all isolates were positive ESBL E. coli (resisting all applied antibiotics in this media, i.e., ceftazidime, cefotaxime, ceftriaxone, aztreonam, and fluconazole), as shown in Figure 1.

\subsection{Molecular Detection and Identity Matrices}

All screened ESBL genes were detected with a different ratio among the chicken isolates. The highest detected genes were bla $a_{\text {CTX-M group } 9}(n=36 / 56)$ and bla TEM $_{\text {T }}(n=33 / 56)$. This was followed by blaPER $(n=27 / 56)$. The bla OXA group 2 was found the lowest and was detected only once, as shown in Table 5.

Table 5. PCR results of chicken (56) and human (9) samples for detection resistance-associated genes.

\begin{tabular}{ccc}
\hline \multirow{2}{*}{ Antibiotic Resistance Genes } & PCR Result: Positive Result/Total Examined Isolates (\%) \\
\cline { 2 - 3 } & Poultry & Human \\
\hline bla & $33 / 56(58.9 \%)$ & $0 / 9(0 \%)$ \\
bla & $7 / 56(12.5 \%)$ & $0 / 9(0 \%)$ \\
bla $_{\text {OXA group }}$ & $1 / 56(1.8 \%)$ & $0 / 9(0 \%)$ \\
bla $_{\text {OXA group } 10}$ & $9 / 56(16.1 \%)$ & $0 / 9(0 \%)$ \\
bla & $10 / 56(17.9 \%)$ & $2 / 9(22.2 \%)$ \\
bla & $27 / 56(48.2 \%)$ & $0 / 9(0 \%)$ \\
bla & $14 / 56(25 \%)$ & $0 / 9(0 \%)$ \\
bla $_{\text {CTX-M group } 1}$ & $19 / 56(33.9 \%)$ & $9 / 9(100 \%)$ \\
bla $_{\text {CTX-M group } 9}$ & $36 / 56(65.3 \%)$ & $9 / 9(100 \%)$ \\
\hline
\end{tabular}

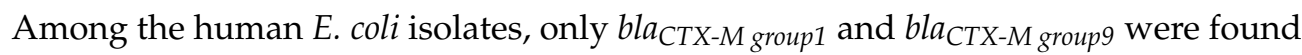
in all isolates. The bla $a_{\text {GES }}$ was found in 2 of 9 . All remaining genes were not detected in 


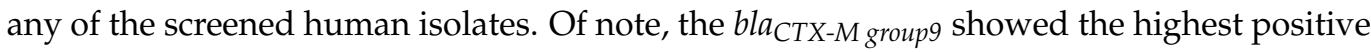
number in both chicken and human isolates.

Furthermore, nucleotide similarity was calculated between chicken and human isolates based on the sequence generated from the six housekeeping genes named $a d k, f u m C$, gyrB, $i c d, m d h$, and purA. Identity of $100 \%$ has been found in fumC and gyrB among the chicken and human isolates. Interestingly, one human isolate (S-6) showed higher similarity for its adk and purA genes with the chickens isolates than the other human isolate. As shown in Figure 2.

adk

\begin{tabular}{|l|l|l|l|l|l|}
\hline & S-5 & S-6 & S-18 & S-46 & S-51 \\
\hline S-5 & & 89 & 90 & 90 & 90 \\
\hline S-6 & 89 & & 98 & 98 & 98 \\
\hline S-18 & 90 & 98 & & 100 & 99 \\
\hline S-46 & 90 & 98 & 100 & & 99 \\
\hline S-51 & 90 & 98 & 99 & 99 & \\
\hline
\end{tabular}

purA

\begin{tabular}{|l|l|l|l|l|l|}
\hline & S-5 & S-6 & S-18 & S-46 & S-51 \\
\hline S-5 & & 91 & 89 & 90 & 88 \\
\hline S-6 & 91 & & 99 & 100 & 100 \\
\hline S-18 & 89 & 99 & & 100 & 100 \\
\hline S-46 & 90 & 100 & 100 & & 100 \\
\hline S-51 & 88 & 100 & 100 & 100 & \\
\hline
\end{tabular}

fumC

\begin{tabular}{|l|l|l|l|l|l|}
\hline & S-5 & S-6 & S-18 & S-46 & S-51 \\
\hline S-5 & & 100 & 100 & 100 & 100 \\
\hline S-6 & 100 & & 100 & 100 & 100 \\
\hline S-18 & 100 & 100 & & 100 & 100 \\
\hline S-46 & 100 & 100 & 100 & & 100 \\
\hline S-51 & 100 & 100 & 100 & 100 & \\
\hline
\end{tabular}

gyrB
\begin{tabular}{|l|l|l|l|l|l|}
\hline & S-5 & S-6 & S-18 & S-46 & S-51 \\
\hline S-5 & & 100 & 100 & 100 & 100 \\
\hline S-6 & 100 & & 100 & 100 & 100 \\
\hline S-18 & 100 & 100 & & 100 & 100 \\
\hline S-46 & 100 & 100 & 100 & & 100 \\
\hline S-51 & 100 & 100 & 100 & 100 & \\
\hline
\end{tabular}

icd

\begin{tabular}{|l|l|l|l|l|l|}
\hline & S-5 & S-6 & S-18 & S-46 & S-51 \\
\hline S-5 & & 100 & 98 & 97 & 98 \\
\hline S-6 & 100 & & 99 & 98 & 98 \\
\hline S-18 & 98 & 99 & & 99 & 100 \\
\hline S-46 & 97 & 98 & 99 & & 99 \\
\hline S-51 & 98 & 98 & 100 & 99 & \\
\hline
\end{tabular}

mdh

\begin{tabular}{|l|l|l|l|l|l|}
\hline & S-5 & S-6 & S-18 & S-46 & S-51 \\
\hline S-5 & & 100 & 96 & 99 & 100 \\
\hline S-6 & 100 & & 97 & 99 & 100 \\
\hline S-18 & 96 & 97 & & 94 & 96 \\
\hline S-46 & 99 & 99 & 94 & & 99 \\
\hline S-51 & 100 & 100 & 96 & 99 & \\
\hline
\end{tabular}

Figure 2. Nucleotide similarity between chicken samples (S18, S46, and S51) and human samples (S5 and S6).

\section{Discussion}

Unmanaged use of antibacterial drugs in human, veterinary, and even agricultural therapy has been proposed as a major cause for the selection and global spread of superbugs, including ESBL-variants [25,26]. Animal feed, particularly chicken feed, is highly supplemented with extended-spectrum antibiotics as prophylaxis/treatment or growth promotion. Generally, sub-therapeutic use of antibiotics in livestock including chicken may contribute to the global prevalence of resistant bugs such as ESBL-producing E. coli in the environment, posing a major health threat to human. Infections with ESBL-producing bacteria can be associated to treatment failure using common antibiotics, which may turn into a global health problem [2,7]. The risk for the transmission of ESBL-producing E. coli between chicken or chicken food products and humans has been highlighted in previous studies [11]; however, from Egypt, limited data on the spread between chickens and humans are available focusing only on either chickens or humans [17].

Here, we investigated the incidence and genetic relationship of ESBL-producing E. coli among chicken in three governorates in the northern part of Egypt. A total of 120 diseased chicken farms and an additionally nine fecal samples from diseased humans were subjected to primary bacteriological and biochemical analysis. In total, $46.7 \%$ of the examined chicken samples and $100 \%$ of the human samples tested positive for E. coli. Furthermore, serotyping analysis assigned all the isolates to O types, in line with Braun et al. [27], who demonstrated that ESBL-producing E. coli from Egyptian cattle are mainly O serotype [27]. Furthermore, ESBL-producers were detected using phenotypic characterization, reporting a high carriage of ESBL-producing E. coli in chicken isolates (75\%). The reported high incidence of ESBL producers in chicken offal suggesting a potential contribution to the high detection rate of these superbugs in human fecal samples (88.9\%). Since chicken-offal (liver, gizzard, and heart) is a popular fast food in Egypt and many developing countries as it is a cheap, easily 
prepared, and a good source of proteins [28]. The prevalence of ESBL-E. coli in chicken offal has been previously reported in Egypt and particularly in cities of northern Egypt. Studies in developing countries demonstrated ESBL-E. coli in chicken-offal $[29,30]$. In the other hand, lower incidence of ESBL-E. coli was described among diseased chickens (37.8), farm workers (37.8), and in the environment (24.3\%) in Nigeria [31].

In addition to ESBL-production, the antibiotic resistance profile revealed that poultry and human isolates expressed a similar antibiotic resistance profile, including high resistance to ampicillin, amoxicillin-clavulanic acid, and sulfamethoxazole-trimethoprim. This is consistent with former reports that showed similar resistance pattern with ESBL-producing E. coli isolated from frozen chicken meat in Bangladesh [32] and broiler farms in the Philippines [33]. Moreover, studies in Japan and Korea recorded resistance of ESBL-producing E. coli associated with high resistance to ampicillin, amoxicillin, and sulfamethoxazoletrimethoprim $[34,35]$. The ESBL phenotypes were further confirmed using PCR, showing that among the genes responsible for ESBL resistance, $b l a_{C T X-M ~ g r o u p g}$, and $b l a_{T E M}$ were the highly predominant in chicken isolates followed with $b l a_{P E R}$ and $b l a_{c t x-M}$ group 1 . In great consistent with recent study in Japan that showed high prevalence rate of CTX-M and TEM families between ESBL-producing Enterobacteria isolated from domestic and farm

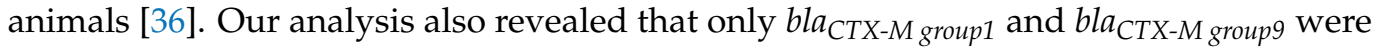
detected in human isolates and the individual data of chicken isolates revealed that the bla $a_{T E M}$ and bla $a_{C T X-M g r o u p g}$ are common in Sharqia governorate, $b l a_{T E M}$ and/or bla $a_{S H V}$ with bla $a_{C T X-M g r o u p 1}$ and/or bla ${ }_{C T X-M g r o u p 9}$ are common in Dakahlia governorate, and $b l a_{T E M}$ is a common gene present in Giza governorate. Moreover, a number of peer-reviewed articles, which included $1329 \mathrm{E}$. coli isolates from humans and various farm animals, including broilers, showed that $\geq 70 \%$ of the animal isolates and $\geq 50 \%$ of the human isolates widely harbor ESBL genes belonging to the CTX-M family, or the combinations of CTX-M + TEM or SHV + TEM families [37]. The ESBL resistance-associated genes $b l a_{T E M}, b l a_{S H V}$, and bla $_{\mathrm{CMY}}$ were previously detected in Enterobacteriaceae isolates from healthy chickens [17] and heart blood from septicemic chickens in Egypt [38]. Another surveillance study also reported significant prevalence of bla $a_{C T X-M}$ gene among ESBL-producing E. coli isolates from offal samples collected from 20 chicken farms distributed in four governorates in Egypt [39].

The bla CTX-M family is known with conferring resistance against to cefotaxime, one of the widely used antibiotics in veterinary medicine. This family was detected in livestock animals in Egypt and hospitalized patients in Alexandria, Egypt [27] and many food chain animals in different countries [40].

Furthermore, sequencing analysis revealed a significant degree of identity $(>90 \%)$ among the ESBL-producing isolates from chicken as well as isolates retrieved from humans. This finding is similar to that obtained by Dahms et al. showing that ESBL-human isolate shared an identical CTX-M allele to the isolate found in the cattle fecal sample from the same farm [41]. Phenotypic and genotypic analysis indicates significant similarity between ESBL-producing E. coli from chicken and human, suggesting a potential transmission of these superbugs from chicken to human. Food of animal origin was recognized as the primary source of human colonization or infection with ESBL bugs [15,16,42]. Furthermore, a number of studies in many European countries reported contamination of chicken meat with ESBL-producing E. coli [16,43]. Globally, chickens are the most consumed animal, and contamination of these food sources with ESBL bugs may function as an effective disseminator of these bugs to humans. A systemic review study also attributed the high incidence of human colonization with ESBL-producing E. coli to direct or indirect contact with animals (via consumption) [44]. However, while our data suggested a potential transmission of ESBL-E. coli from chickens to humans, we admit that there are limitations in our study, as the chicken isolates were collected from the northern part of Egypt and human isolates from the southern Egypt. It may be difficult for a person from southern Egypt to have direct or indirect contact with chickens in northern Egypt, although it is 
not impossible, since many Egyptians from southern Egypt travel daily to northern Egypt, spend the day there, and then return south. Furthermore, northern Egypt has the highest number of large poultry enterprises compared to the other Egyptian cities [45]. Therefore, northern Egypt pumps frozen chicken and chicken products including chicken offal all over the country. Based on the nature of chicken products circulated throughout the country, the possible spread of infection among the population is not impossible.

\section{Conclusions}

The study shows the phenotypic and genetic links of ESBL-producing E. coli isolated from chickens and humans in Egypt, suggesting a possibility of transmission among chickens and humans. This highlights the need of continuous monitoring and obtaining more samples at a closer proximity "chicken-human interface". In addition, deep genetic studies using whole genome sequencing is required for better understanding of the genetic relationship between animal and human isolates. Ultimately, a "One Health" approach should be more active in Egypt to avoid rapid evolution of antibiotic-resistance bacteria.

Author Contributions: Conceptualization, H.B., S.F.A. and H.R.A.; methodology, H.B., N.M.H., S.M.E. and H.R.A.; software, E.K., A.I.M. and H.R.A.; validation, H.B., R.M.R., S.M.E., N.M.H. and H.R.A.; formal analysis, H.B., M.A.S., S.F.A., S.M.E. and H.R.A.; investigation, H.B., R.M.R., S.F.A., A.I.M., S.F.A. and H.R.A.; resources, H.B., S.F.A., E.K., N.M.H. and M.A.S.; data curation, H.B., R.M.R. and H.R.A.; writing — original draft preparation, H.B., R.M.R., H.R.A. and S.M.E.; writing-review and editing, H.B., R.M.R. and H.R.A. All authors have read and agreed to the published version of the manuscript.

Funding: This research received no external funding.

Institutional Review Board Statement: Animal sample collection in this study was legally approved by the Committee of Ethics of Animal Experiments at the Animal Health Research Institute, Egypt, under protocol number (AHRI-42429). However, chicken samples were collected during the regular investigation routine of the broiler farm. Approval for human samples were also obtained, the study was approved by Faculty of Pharmacy Ethical committee, Kafrelsheikh University. Fecal human samples were collected from diseased people and submitted to a bacteriology unit in RLQP laboratory for bacteriological analysis.

Informed Consent Statement: Patient consent was waived due to no minimal risk or harm being involved to humans, as fecal samples were collected from a bacteriology laboratory where patients were voluntarily admitted with a referral from their physician. The bacteriology laboratory which provided the human samples signed a letter to confirm that authors didn't approach humans to collect samples and that authors did not have access to the patient's personal information (samples were provided anonymously). The laboratory also agreed that the samples can be used for research purposes.

Data Availability Statement: No supporting data was included.

Acknowledgments: The authors acknowledge Asmaa Gahlan, El-Wadi Al-Jadid University for collecting the human samples.

Conflicts of Interest: The authors declare no conflict of interest.

\section{References}

1. Percival, S.L.; Williams, D.W. Chapter Six-Escherichia coli. In Microbiology of Waterborne Diseases, 2nd ed.; Percival, S.L., Yates, M.V., Williams, D.W., Chalmers, R.M., Gray, N.F., Eds.; Academic Press: London, UK, 2014; pp. 89-117.

2. Poirel, L.; Madec, J.Y.; Lupo, A.; Schink, A.K.; Kieffer, N.; Nordmann, P.; Schwarz, S. Antimicrobial Resistance in Escherichia coli. Microbiol. Spectr. 2018, 6. [CrossRef]

3. Giufrè, M.; Mazzolini, E.; Cerquetti, M.; Brusaferro, S. Extended-spectrum $\beta$-lactamase-producing Escherichia coli from extraintestinal infections in humans and from food-producing animals in Italy: A 'One Health' study. Int. J. Antimicrob. Agents 2021, 58, 106433. [CrossRef] [PubMed]

4. Cardozo, M.V.; Liakopoulos, A.; Brouwer, M.; Kant, A.; Pizauro, L.J.L.; Borzi, M.M.; Mevius, D.; de Ávila, F.A. Occurrence and Molecular Characteristics of Extended-Spectrum Beta-Lactamase-Producing Enterobacterales Recovered From Chicken, Chicken Meat, and Human Infections in Sao Paulo State, Brazil. Front. Microbiol. 2021, 12, 628738. [CrossRef] [PubMed] 
5. McEwen, S.A.; Collignon, P.J. Antimicrobial Resistance: A One Health Perspective. Microbiol. Spectr. 2018, 6. [CrossRef]

6. White, A.; Hughes, J.M. Critical Importance of a One Health Approach to Antimicrobial Resistance. EcoHealth 2019, 16, 404-409. [CrossRef] [PubMed]

7. Rousham, E.K.; Unicomb, L.; Islam, M.A. Human, animal and environmental contributors to antibiotic resistance in low-resource settings: Integrating behavioural, epidemiological and One Health approaches. Proc. Biol. Sci. 2018, 285. [CrossRef]

8. Coppola, N.; Freire, B.; Umpiérrez, A.; Cordeiro, N.F.; Ávila, P.; Trenchi, G.; Castro, G.; Casaux, M.L.; Fraga, M.; Zunino, P.; et al. Transferable Resistance to Highest Priority Critically Important Antibiotics for Human Health in Escherichia coli Strains Obtained From Livestock Feces in Uruguay. Front. Vet. Sci. 2020, 7, 588919. [CrossRef] [PubMed]

9. Bubpamala, J.; Khuntayaporn, P.; Thirapanmethee, K.; Montakantikul, P.; Santanirand, P.; Chomnawang, M.T. Phenotypic and genotypic characterizations of extended-spectrum beta-lactamase-producing Escherichia coli in Thailand. Infect. Drug Resist. 2018, 11, 2151-2157. [CrossRef]

10. Chishimba, K.; Hang'Ombe, B.; Muzandu, K.; Mshana, S.; Matee, M.; Nakajima, C.; Suzuki, Y. Detection of extended-spectrum beta-lactamase-producing Escherichia coli in market-ready chickens in Zambia. Int. J. Microbiol. 2016, 2016. [CrossRef]

11. Falgenhauer, L.; Imirzalioglu, C.; Oppong, K.; Akenten, C.W.; Hogan, B.; Krumkamp, R.; Poppert, S.; Levermann, V.; Schwengers, O.; Sarpong, N. Detection and characterization of ESBL-producing Escherichia coli from humans and poultry in Ghana. Front. Microbiol. 2019, 9, 3358. [CrossRef]

12. Eibach, D.; Dekker, D.; Boahen, K.G.; Akenten, C.W.; Sarpong, N.; Campos, C.B.; Berneking, L.; Aepfelbacher, M.; Krumkamp, R.; Owusu-Dabo, E. Extended-spectrum beta-lactamase-producing Escherichia coli and Klebsiella pneumoniae in local and imported poultry meat in Ghana. Vet. Microbiol. 2018, 217, 7-12. [CrossRef] [PubMed]

13. Guenther, S.; Aschenbrenner, K.; Stamm, I.; Bethe, A.; Semmler, T.; Stubbe, A.; Stubbe, M.; Batsajkhan, N.; Glupczynski, Y.; Wieler, L.H.; et al. Comparable high rates of extended-spectrum-beta-lactamase-producing Escherichia coli in birds of prey from Germany and Mongolia. PLoS ONE 2012, 7, e53039. [CrossRef] [PubMed]

14. Kluytmans, J.A.; Overdevest, I.T.; Willemsen, I.; Kluytmans-van den Bergh, M.F.; van der Zwaluw, K.; Heck, M.; Rijnsburger, M.; Vandenbroucke-Grauls, C.M.; Savelkoul, P.H.; Johnston, B.D.; et al. Extended-spectrum $\beta$-lactamase-producing Escherichia coli from retail chicken meat and humans: Comparison of strains, plasmids, resistance genes, and virulence factors. Clin. Infect. Dis. 2013, 56, 478-487. [CrossRef] [PubMed]

15. Kola, A.; Kohler, C.; Pfeifer, Y.; Schwab, F.; Kühn, K.; Schulz, K.; Balau, V.; Breitbach, K.; Bast, A.; Witte, W.; et al. High prevalence of extended-spectrum- $\beta$-lactamase-producing Enterobacteriaceae in organic and conventional retail chicken meat, Germany. $J$. Antimicrob. Chemother. 2012, 67, 2631-2634. [CrossRef] [PubMed]

16. Leverstein-van Hall, M.A.; Dierikx, C.M.; Cohen Stuart, J.; Voets, G.M.; van den Munckhof, M.P.; van Essen-Zandbergen, A.; Platteel, T.; Fluit, A.C.; van de Sande-Bruinsma, N.; Scharinga, J.; et al. Dutch patients, retail chicken meat and poultry share the same ESBL genes, plasmids and strains. Clin. Microbiol. Infect. 2011, 17, 873-880. [CrossRef] [PubMed]

17. Moawad, A.A.; Hotzel, H.; Neubauer, H.; Ehricht, R.; Monecke, S.; Tomaso, H.; Hafez, H.M.; Roesler, U.; El-Adawy, H. Antimicrobial resistance in Enterobacteriaceae from healthy broilers in Egypt: Emergence of colistin-resistant and extendedspectrum $\beta$-lactamase-producing Escherichia coli. Gut. Pathog. 2018, 10, 39. [CrossRef] [PubMed]

18. Rahman, M.M.; Husna, A.; Elshabrawy, H.A.; Alam, J.; Runa, N.Y.; Badruzzaman, A.T.M.; Banu, N.A.; Al Mamun, M.; Paul, B.; Das, S.; et al. Isolation and molecular characterization of multidrug-resistant Escherichia coli from chicken meat. Sci. Rep. 2020, 10, 21999. [CrossRef]

19. Nolan, L.; Barnes, H.; Vaillancourt, J.; Abdul-Aziz, T.; Logue, C. Diseases of Poultry, 13th ed.; Swayne, D.E., Ed.; Wiley-Blackwell: Hoboken, NJ, USA, 2013.

20. World Health Organization. Manual for the Laboratory Identification and Antimicrobial Susceptibility Testing of Bacterial Pathogens of Public Health Importance in the Developing World: Haemophilus influenzae, Neisseria meningitidis, Streptococcus pneumoniae, Neisseria gonorrhoea, Salmonella serotype Typhi, Shigella, and Vibrio cholerae / Principal authors: Mindy J. Perilla ... [et al.]; World Health Organization: Geneva, Switzerland, 2003.

21. CLSI. Performance Standards for Antimicrobial Susceptibility Testing; CLSI: Wayne, PA, USA, 2021.

22. Anago, E.; Ayi-Fanou, L.; Akpovi, C.D.; Hounkpe, W.B.; Agassounon-Djikpo Tchibozo, M.; Bankole, H.S.; Sanni, A. Antibiotic resistance and genotype of beta-lactamase producing Escherichia coli in nosocomial infections in Cotonou, Benin. Ann. Clin. Microbiol. Antimicrob. 2015, 14, 5. [CrossRef]

23. Ryoo, N.H.; Kim, E.C.; Hong, S.G.; Park, Y.J.; Lee, K.; Bae, I.K.; Song, E.H.; Jeong, S.H. Dissemination of SHV-12 and CTX-M-type extended-spectrum beta-lactamases among clinical isolates of Escherichia coli and Klebsiella pneumoniae and emergence of GES-3 in Korea. J. Antimicrob. Chemother. 2005, 56, 698-702. [CrossRef]

24. Wirth, T.; Falush, D.; Lan, R.; Colles, F.; Mensa, P.; Wieler, L.H.; Karch, H.; Reeves, P.R.; Maiden, M.C.; Ochman, H.; et al. Sex and virulence in Escherichia coli: An evolutionary perspective. Mol. Microbiol. 2006, 60, 1136-1151. [CrossRef]

25. Hosuru Subramanya, S.; Bairy, I.; Nayak, N.; Padukone, S.; Sathian, B.; Gokhale, S. Low rate of gut colonization by extendedspectrum $\beta$-lactamase producing Enterobacteriaceae in HIV infected persons as compared to healthy individuals in Nepal. PLoS ONE 2019, 14, e0212042. [CrossRef] [PubMed]

26. Yang, Y.; Ashworth, A.J.; Willett, C.; Cook, K.; Upadhyay, A.; Owens, P.R.; Ricke, S.C.; DeBruyn, J.M.; Moore, P.A., Jr. Review of Antibiotic Resistance, Ecology, Dissemination, and Mitigation in U.S. Broiler Poultry Systems. Front. Microbiol. 2019, 10, 2639. [CrossRef] [PubMed] 
27. Braun, S.D.; Ahmed, M.F.; El-Adawy, H.; Hotzel, H.; Engelmann, I.; Weiß, D.; Monecke, S.; Ehricht, R. Surveillance of ExtendedSpectrum Beta-Lactamase-Producing Escherichia coli in Dairy Cattle Farms in the Nile Delta, Egypt. Front. Microbiol. 2016, 7, 1020. [CrossRef] [PubMed]

28. Hassanin, F.S.; Hassan, M.A.; Shaltout, F.A.; Shawqy, N.A.; Abd-Elhameed, G.A. Bacteriological criteria of chicken giblets. Benha Vet. Med. J. 2017, 33, 447-456. [CrossRef]

29. Al-Agamy, M.H. Phenotypic and molecular characterization of extended-spectrum $\beta$-lactamases and AmpC $\beta$-lactamases in Klebsiella pneumoniae. Pak. J. Pharm. Sci. 2013, 26.

30. Benklaouz, M.B.; Aggad, H.; Benameur, Q. Resistance to multiple first-line antibiotics among Escherichia coli from poultry in Western Algeria. Vet. World 2020, 13, 290. [CrossRef]

31. Aworh, M.K.; Kwaga, J.; Okolocha, E.; Harden, L.; Hull, D.; Hendriksen, R.S.; Thakur, S. Extended-spectrum B-lactamaseproducing Escherichia coli among humans, chickens and poultry environments in Abuja, Nigeria. One Health Outlook 2020, 2, 8 [CrossRef]

32. Parvin, M.S.; Talukder, S.; Ali, M.Y.; Chowdhury, E.H.; Rahman, M.T.; Islam, M.T. Antimicrobial Resistance Pattern of Escherichia coli Isolated from Frozen Chicken Meat in Bangladesh. Pathogens 2020, 9, 420. [CrossRef]

33. Gundran, R.S.; Cardenio, P.A.; Villanueva, M.A.; Sison, F.B.; Benigno, C.C.; Kreausukon, K.; Pichpol, D.; Punyapornwithaya, V. Prevalence and distribution of bla(CTX-M), bla(SHV), bla(TEM) genes in extended- spectrum $\beta$ - lactamase- producing E. coli isolates from broiler farms in the Philippines. BMC Vet. Res. 2019, 15, 227. [CrossRef]

34. Seo, K.W.; Kim, Y.B.; Jeon, H.Y.; Lim, S.K.; Lee, Y.J. Comparative genetic characterization of third-generation cephalosporinresistant Escherichia coli from chicken meat produced by integrated broiler operations in South Korea. Poult. Sci. 2018, 97, 2871-2879. [CrossRef]

35. Kawamura, K.; Goto, K.; Nakane, K.; Arakawa, Y. Molecular epidemiology of extended-spectrum $\beta$-lactamases and Escherichia coli isolated from retail foods including chicken meat in Japan. Foodborne Pathog. Dis. 2014, 11, 104-110. [CrossRef] [PubMed]

36. Ejaz, H.; Younas, S.; Abosalif, K.O.A.; Junaid, K.; Alzahrani, B.; Alsrhani, A.; Abdalla, A.E.; Ullah, M.I.; Qamar, M.U.; Hamam, S.S.M. Molecular analysis of blaSHV, blaTEM, and blaCTX-M in extended-spectrum $\beta$-lactamase producing Enterobacteriaceae recovered from fecal specimens of animals. PLoS ONE 2021, 16, e0245126. [CrossRef] [PubMed]

37. Valentin, L.; Sharp, H.; Hille, K.; Seibt, U.; Fischer, J.; Pfeifer, Y.; Michael, G.B.; Nickel, S.; Schmiedel, J.; Falgenhauer, L.; et al. Subgrouping of ESBL-producing Escherichia coli from animal and human sources: An approach to quantify the distribution of ESBL types between different reservoirs. Int. J. Med. Microbiol. 2014, 304, 805-816. [CrossRef] [PubMed]

38. Ahmed, A.M.; Shimamoto, T.; Shimamoto, T. Molecular characterization of multidrug-resistant avian pathogenic Escherichia coli isolated from septicemic broilers. Int. J. Med. Microbiol. 2013, 303, 475-483. [CrossRef] [PubMed]

39. El-Shazly, D.; Nasef, S.; Mahmoud, F.; Jonas, D. Expanded spectrum $\beta$-lactamase producing Escherichia coli isolated from chickens with colibacillosis in Egypt. Poult. Sci. 2017, 96, 2375-2384. [CrossRef] [PubMed]

40. Hartmann, A.; Locatelli, A.; Amoureux, L.; Depret, G.; Jolivet, C.; Gueneau, E.; Neuwirth, C. Occurrence of CTX-M Producing Escherichia coli in Soils, Cattle, and Farm Environment in France (Burgundy Region). Front. Microbiol. 2012, 3, 83. [CrossRef]

41. Dahms, C.; Hübner, N.O.; Kossow, A.; Mellmann, A.; Dittmann, K.; Kramer, A. Occurrence of ESBL-Producing Escherichia coli in Livestock and Farm Workers in Mecklenburg-Western Pomerania, Germany. PLoS ONE 2015, 10, e0143326. [CrossRef] [PubMed]

42. Overdevest, I.; Willemsen, I.; Rijnsburger, M.; Eustace, A.; Xu, L.; Hawkey, P.; Heck, M.; Savelkoul, P.; Vandenbroucke-Grauls, C.; van der Zwaluw, K.; et al. Extended-spectrum $\beta$-lactamase genes of Escherichia coli in chicken meat and humans, The Netherlands. Emerg. Infect. Dis. 2011, 17, 1216-1222. [CrossRef]

43. Doi, Y.; Paterson, D.L.; Egea, P.; Pascual, A.; López-Cerero, L.; Navarro, M.D.; Adams-Haduch, J.M.; Qureshi, Z.A.; Sidjabat, H.E.; Rodríguez-Baño, J. Extended-spectrum and CMY-type beta-lactamase-producing Escherichia coli in clinical samples and retail meat from Pittsburgh, USA and Seville, Spain. Clin. Microbiol. Infect. 2010, 16, 33-38. [CrossRef]

44. Pormohammad, A.; Nasiri, M.J.; Azimi, T. Prevalence of antibiotic resistance in Escherichia coli strains simultaneously isolated from humans, animals, food, and the environment: A systematic review and meta-analysis. Infect. Drug Resist. 2019, 12, $1181-1197$. [CrossRef] [PubMed]

45. El Nagar, A.; Ibrahim, A. Case study of the Egyptian poultry sector. In Proceedings of the International Poultry Conference, Bangkok, Thailand, 5-7 November 2007. 